\title{
Material (re)contextualization: goal establishment in means-oriented architectural design
}

\author{
N. C. Pereira ${ }^{1,2}$, S. Datta ${ }^{1}$ \& F. M. Mancini ${ }^{1}$ \\ ${ }^{1}$ Curtin University, Australia \\ ${ }^{2}$ Instituto Federal de São Paulo and Cnpq, Brazil
}

\begin{abstract}
The most common starting point for design is the definition of the design problem. This is commonly expressed as goals and objectives to be met and referred to as "goals-oriented" design. A reverse process for conceiving architecture, called "means-oriented" design uses available materials and means as a starting point for design and then establishes a process for detailing and objectives to be reached. Designers are directed by discarded materials, elements or structures, with no initial spatial objectives. Means-oriented design is therefore a novel approach in which designers and architects research the affordances of means before they establish a process. It brings the importance of materiality back to design science and encourage adaptive reuse within the process. Early consideration of materiality during the design development resituates older materials within a new context. In light of the above, the main objective of this paper is to identify how goals are built during means-oriented design and how this affects the reuse of materials, elements or structures. The paper reports on the analysis of findings from a learning environment where students were challenged to design and build panels from irregular sized decommissioned weapon parts. Their approach and outcomes for each stage were unfolded and potential influences between internal and external factors were crossed to search patterns upon the definition of proposals and the final product.
\end{abstract}

Keywords: means-oriented design, reuse, design goals, adaptive reuse. 


\section{Introduction}

Architectural design is a science of experimentation which involves several elements. The process is usually informal, intrinsic and personal with no preestablished heuristic for problem solving. Chakrabarti et al. [1] defines design as the practice whereby a story is built to satisfy requirements through development and synthesis of building blocks into meaningful pieces to fulfil needs and desires of a specific problem. According to Oxman [2], a design story is the meaningful linkage outcome of three basic components or chunks of knowledge: issue, concept, form. Nevertheless, Eilouti [3] splits the design task into encoding forms, functions, processes, concepts, scenarios, principles and components which requires processing and interpretation to become a meaningful piece.

Despite these diverse views of its structure, design invariably begins with an initial stage focused on a problem or need. In order to set a favorable response for a design question, the designer makes use of different tools and methods and the range of possibilities for the outcome will depend not only on how those are applied, but also on the background built before the process start. Wiggins [4] frames the design worlds in two major groupings: 'Substantive knowledge' bears on what the designer 'knows' and 'Process skills' refers to what a designer 'does'.

Materiality has an important role in architectural design as it affects all aspects of spaces or buildings. It is a dynamic evolving space with light, materiality and narrative in which all formal and tectonic exploration should understand and contemplate the interdependence of these components [5]. For Schön [6], architectural design is an "experimentation that consists in reflective conversation with the "materials' of a design situation".

Architecture is a material based practice with an emphasis on the consideration of materials from the conceptual stages of design to the building delivery stage. With advances in technology and specialized knowledge, the role of designer and maker has become distinct. As the representational knowledge has grown, the reflection and understanding of materials in architectural design has decreased in contemporary practice. Architects are seen as form givers who relegate material to the empty spaces between lines. For instance, in contemporary professional practice, drawings describe form while language is used for the materials in notes on working drawings or/and in the specification [7]. Also university students are often encouraged to model using only white or other neutral single color materials. This approach places architectural design as a mode of representation and reduces a building to an assembly of material systems.

Despite this, materials and materiality in architectural design remains a broad topic. On one hand, technological advances have offered endless possibilities of materials for every application in design. The array is so extensive that it is a challenge to make a proper selection, considering the management of the knowledge upon the range of material property data [8,9]. Wright [10] adds that "just as many fascinating different properties as there are different materials that may be used to build a building will continually and naturally qualify, modify and utterly change all architectural form whatsoever." Extending the process supporting material selection is therefore critical for effective utilization of 
alternative materials. Such a method might facilitate a comprehensive screening of the possibilities besides those used in standardized systems.

On the other hand, when the resource is made available as the first step for design and material does not need to be selected (it needs to be applied instead). The designer attempts to contextualize such given or found materials. However, their efforts often fail or cease, as there are no structured design methods to apply besides their imagination and creativity. In this case, the design requires goals construction. While goal construction is widely studied in the case of goal-oriented design, there is a lack in both literature and teaching systems around on how goal construction is achieved in the context of means-oriented design.

Therefore, investigation on the position of materials within the design process can support a further understanding towards the processes for designing. Furthermore, findings on how goal construction is achieved to (re)contextualize materials for architectural purposes will build knowledge for further improvements on extending the use of materials in the early design stages. This knowledge can also enhance the reuse of existing resources and facilitate the extension of their lifecycle flows. Given this scenario, this paper foments the discussion about the challenges of positioning material within the design process, define goals-oriented design and means-oriented design and shows initial evidence on relevant factors when establishing goals in proposals which material come first.

This study is part of a broader research that aims to develop a proposal to increase the efficiency of means-oriented design. This first step is to conceptualize the process and identify aspects of inefficiency to address. Data for this stage was collected in a design learning environment. Thirty-one interior architecture students from Curtin University, Australia, were required to design and build panels from irregular sized decommissioned weapon parts. Observations notes from intuitive thinking and motivations for design decisions were organized, coded and related to the final outcome.

\section{Design approaches based on materiality}

In order to nominate distinct processes used for designing, this research will adopt the expressions 'means-oriented design' (MOD), also known by resource-based design, and 'goal-oriented design' (GOD), suggested by Van Hinte et al. [11]. Discussions on material position are scarce in architectural design research literature. The researcher was interviewed by Van Hinte et al. [11], proposes these views theoretically and was found to be assertive around the theme. In this approach, the main theoretical statement relation is to the significance of the material within the design development. While goal-oriented design is the most common process where the building goal is predefined, means-oriented design begins from the means (or materials) available, with no defined end or objectives.

Goal-oriented design is the prevalent method upon every decision, including materials selection, aims to reach that goal. According to Addis [12], in this classical empirical process, the design team first plans the structure up to the scheme or detailed design and then sources and purchase suitable materials and goods. The architect conceives the elements and systems of building and then 
specifies the materials and components to achieve a given performance and quality. Generally, there already exists an established market where suitable materials and components can be purchased. When dealing with GOD with reclaimed components, no equivalent market exists. Thus, it becomes essential for designers to identify the source of suitable products before detailed design and specification are undertaken.

The process becomes especially complex when the proposal is to carry out the design process whereby its main beginning is guided by availability of materials or goods. Designated as means-oriented design, this practice focuses on material first and then defines objectives (goals) to reach. Within this context, the establishment of the goals of design depends on factors related with the 'means' or materials, such as availability of sources, amount, condition, physical characteristics (form, appearance, resistance, flexibility, durability) hybridism and other layers. MOD begins with limited resources and these become informants that lead the design towards a typically less pre-determined goal.

Although means-oriented design is a common practice for designers who look at materiality as an opportunity, it occurs randomly with unstructured series of attempts, failures and improvisation and it is often approached as a craft activity.

According to Fry [13], design starts before the process and it is not finished when it is done. This is the proposal of MOD: re-contextualize outdated, discarded, unwanted existing materials, elements, structures or buildings into a meaningful project and give their life cycle a second chance to be extended. When looking properly to what is already there, infinite possibilities might arise. This approach takes place in different architectural scales. A pet bottle can become a lamp, in Interior scale. In Architecture, old fridges turn into a vending bar and in urban scale, an outdated airplane composes an interactive pathway at a metropolitan park. Both processes (GOD and MOD) can be overlapped and the emphasis on materials is what differentiates their focus.

Within the academic attempts to frame the design process, the Design Council, London, proposed a flexible non-linear model called Double Diamond. It represents moments of convergence and divergence related to design decisions throughout the design development. It starts with divergent thinking and moves until the ideas are selected and refined [14]. The stages bear comprehensive interpretation and they were applied in this study to systemize and compare usual actions taken during MOD and GOD.

In MOD, material available (including elements, pieces and structures) and all information related consist of the constants of the process. The skills, experience, actions and environment of the designer(s) englobe the variables. The interaction concerning constants and variables impacts the design decisions and the final outcome.

MOD demands goal establishment throughout the design, even during delivery. From this comparison frame, the main differences between the approaches is that in MOD, unconventionally, material needs to be learned rather than selected, it has to be prepared (recondition/refurbish) and redesign episodes are recurrent. These aspects deserve special consideration as potential factors related to the efficiency of MOD. 


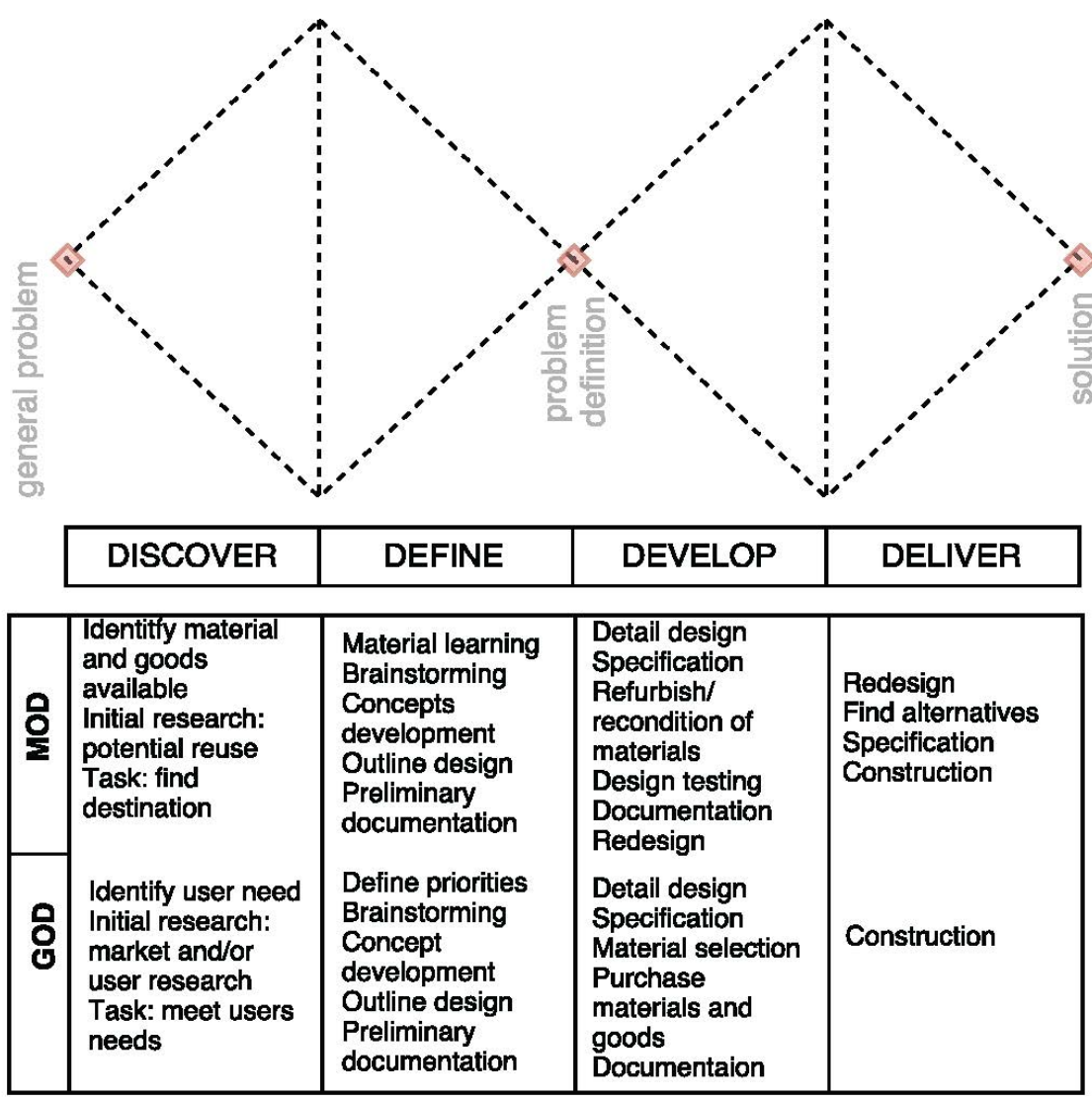

Figure 1: Double Diamond [15] (adapted by the authors).

\section{Material selection in goal-oriented architectural design}

Every element will drastically transform (or become another) by having changed what makes it exist: material. Form follows material and this is obvious in architecture. In most buildings, materials are determined by "local availability, current practice and experience, cost and construction expediency, and to a lesser extent, design and aesthetic preferences" [8].

There are numerous methodologies for material selection in engineering and industrial design. Ashby [9] suggests some methods for product design: by analysis; by synthesis; by similarity; by inspiration; and a combination between them. Another proposal describes 'materials screening methods', including cost per unit property method; chart method; questionnaire method; materials in products selection tools; artificial intelligence methods and 'materials comparing and choosing methods': Multiple attribute decision making approaches; Fuzzy multi-criteria decision-making methods; multiple objective decision making approaches; optimization methods [16]. 
In architecture, however, the designer looks for experimentation, sensations and specific tactile properties and those tools consider technical aspects. It is usually known requirements such as quantity, form, function, properties and even budget for any particular task, but it is rarely known the material itself. There is a gap on the literature about a material selection tool or process adopted by architects. Usually the criteria are based on designer's background, experience or knowledge, or guided by standardization or stakeholder's interests. Some few borders their choices on libraries of materials in computer based tools.

Wastiels and Wouters [17] identified four themes of material selection considerations by architects: (I) Material properties, (II) Experience, (III) Manufacturing process, and (IV) Context. Akadiri and Olomolaiye [18] propose the Use of Leadership in Energy and Environmental Design (LEED) rating system for building materials selection. Fernandez [8] completes that contemporary architect mainly makes choices that result in "fabricated assemblies of standardized performance attributes", implying that they do not choose for materials but rather for 'material systems'. He adds that limiting the assembly of buildings to the specification of systems would impede the discovery of design possibilities that materials might provide.

An effective material selection process for architecture might narrow the range of possibilities and increase design opportunities. Controversially from engineering design, the perception level required for material in architecture is also form, functional, interactive, virtual or even the non-perception of the material rather than selection based mainly on the cost, strength, availability or environmental compatibility [19].

\section{Goal establishment in means-oriented design}

The four activity groups (discover, define, develop, and deliver) from the double diamond define also, in this work, four stages of goal establishment in MOD. The group of participants of this study played activities related to development and

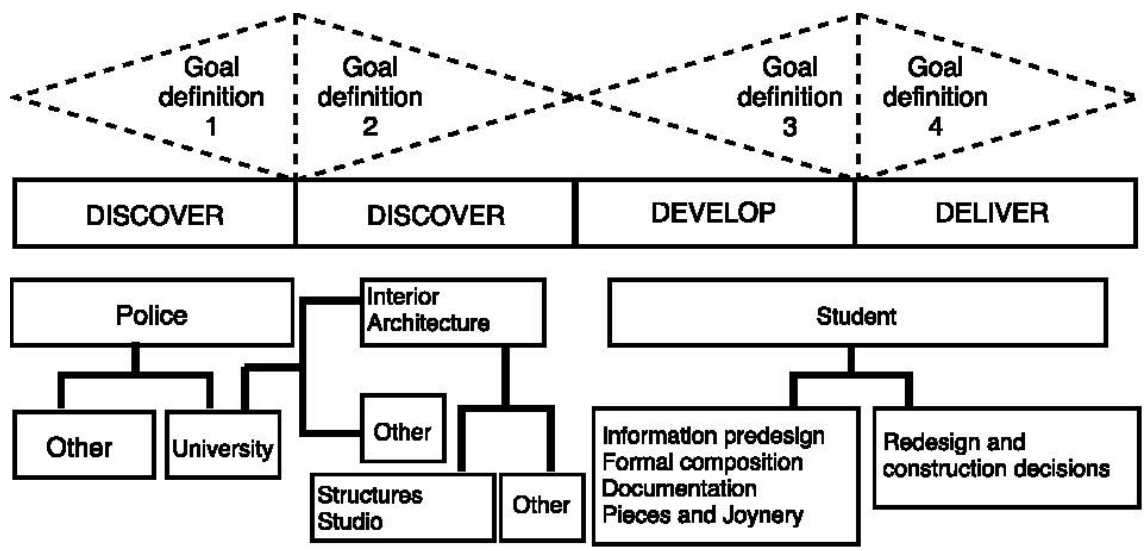

Figure 2: Four stages of goals establishment in means-oriented design. 
delivery stages, but the goal establishment had been happening since before. This project looks at the third and fourth stage of goal definition which the students acted.

Western Australia State Police Department often decommissions fire weapons for diverse reasons. Those pieces of equipment are dismantled, sectioned as to become unutilized for their primary function. The pieces present irregular sizes and vary from parts of wood handles and forestock, metal barrels, metal telescopes, among others, and they were found to be an opportunity for design.
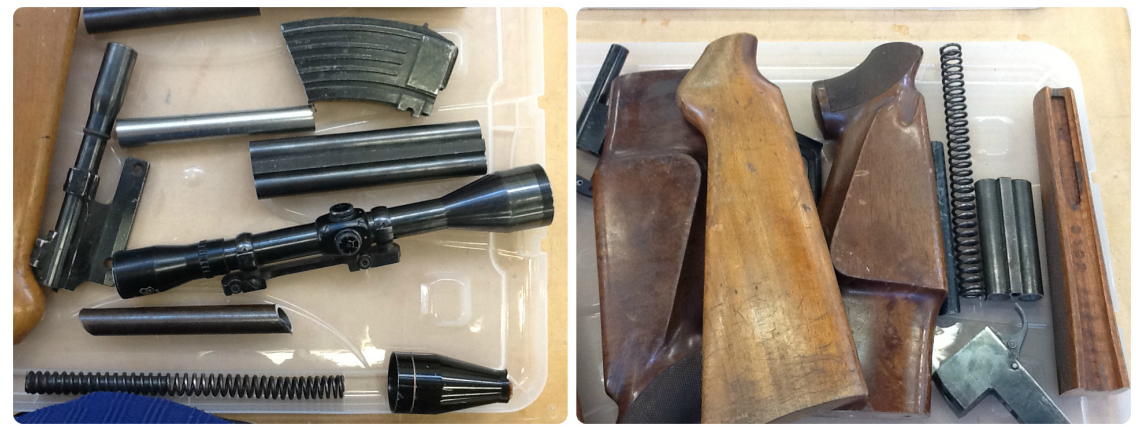

Figure 3: Samples of the material available for the project.

The Structures Studio Unit from Interior Architecture proposal was that the 31 second year students should design and build self-supporting panels measuring $1.2 \mathrm{~m} \times 1.2 \mathrm{~m}$. Firstly, 31 individual proposals were developed and represented through cardboard models. Then 5 were selected from those to complete the deliver stage and to be built with the real pieces. In this phase, the students used the infrastructure from the workshops where they were supervised and offered introductory manufacture training. The students had access to six boxes (seventeen litters each) of pieces when working in the workshops. For health and safety reasons, they were not allowed to remove the pieces from the workshop, take photographs or publish images of the weapon parts before the completion of the project. In the final stages of the design process, four out of five proposal had to be adapted due to unforeseen circumstances. The project lasted 60 days.

Field notes taken during the process were focused on observing predesign approaches, formal composition, documentation methods and redesign strategies. The analysis was built through coding the field notes and outcome models. The codes were defined based on considerations adopted for material selection in GOD, design strategies and documentation, and items related to 'material learning', 'material reconditioning/refurbishment' and 'redesign' for their potential to impact MOD design efficiency. Thirty attributes were categorized and organized into a matrix of codes.

In order to identify factors of influence on the goal establishment process, expected and unexpected outcomes (stability, feasibility, redesign level, handleability and formal exploration) were compared with coding attributes from the following categories: Information predesign; Formal composition; 
Documentation; Pieces and Joinery; Redesign and construction decisions. From thirty-one cardboard proposals, only those five further developed using the real pieces were considered into 'Redesign and construction decisions' category.
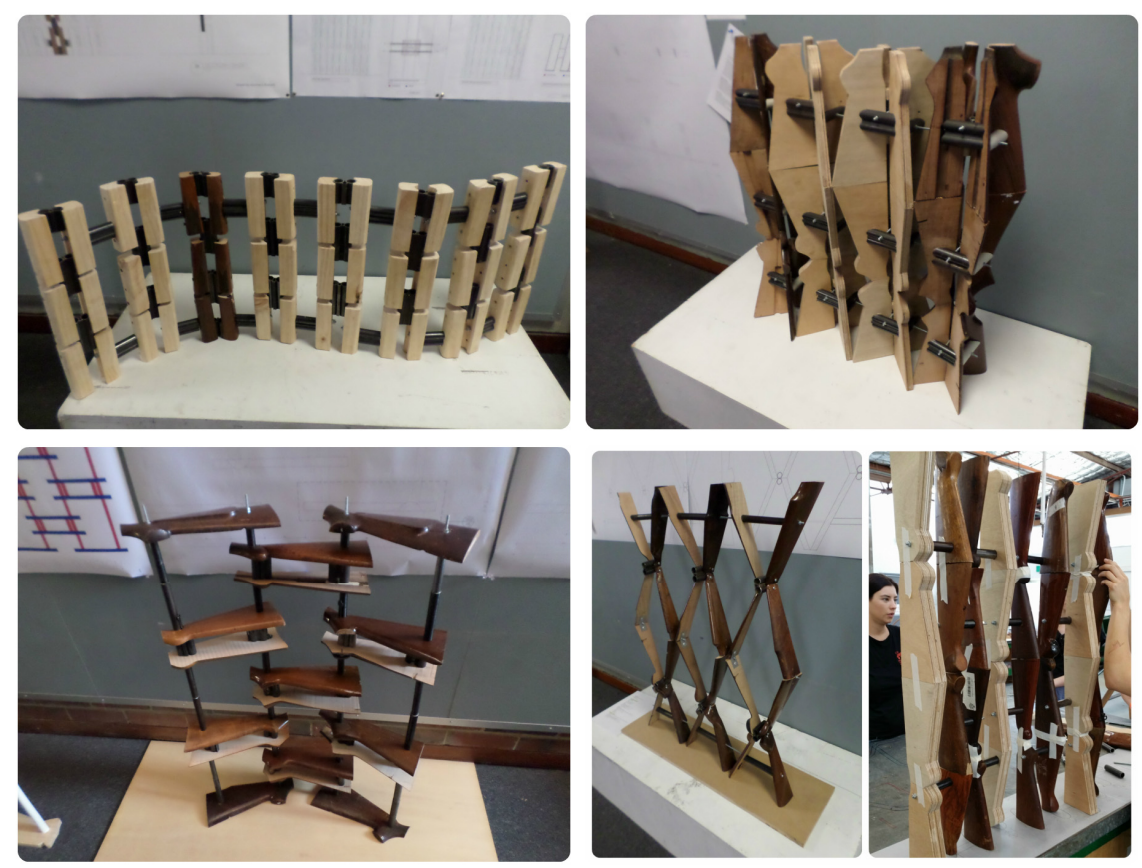

Figure 4: Means-oriented design final models.

Preliminary results have shown that better design outcomes were reached for those designers who manipulated and experimented using more diversity of pieces during predesign stage and applied modules, tridimensional reasoning and exploration of original form of the real pieces. Proposals from complete and reliable documentation, especially those with consideration on joints, clear concepts and precedents research also contributed for better results. The use of digital tools during design has not improved the quality of the projects, as array and copy functions induced the thinking they were working with identical pieces, which caused issues when dealing with real pieces. Students who outsourced the manufacture of the pieces for their panels (cutting, sanding and drilling) had poorer outcomes than those who acquired skills on how to handle the machines available in the workshop.

The most significant problems detected during the process were: connections and details of the pieces that were not considered during planning; cardboard model exceeded the final model expectations; material scarce during construction (disregard of material amount available); material in condition not expected and excess of unnecessary connections, making the manufacture more complex and timing. 


\section{Conclusion}

This study is part of a broader research that aims to develop a proposal to increase the efficiency of means-oriented design. It investigates the challenges of positioning material within the design process, defines goals-oriented design and means-oriented design and shows initial evidence on relevant factors when establishing goals in proposals which material come first.

Firstly, the paper conceptualizes the process and identifies aspects of inefficiency. Data collected from a design learning environment is analyzed to design and build panels from irregular sized decommissioned weapon parts. Observations notes from intuitive thinking and motivations for design decisions were organized, coded and related to the final outcome.

Results have shown that learning characteristics of the resource such as properties, amount, condition, and shape seems to be an important step for an efficient means-oriented design process. Also, more satisfactory outcomes were reached for those designers who manipulated and experimented using more diversity of pieces during predesign stage and applied modules, tridimensional reasoning and exploration of original form of the material. Quality design documentation, clear concepts and precedents research also contributed for better results. While skills on manufacturing seems to facilitate the delivery stages, the application of digital tools deserves caution as it may lead to misconception of the material and cause obstacles during construction.

As a new approach for design research, means-oriented design theory requires further understanding and knowledge only will be built throughout sequential research development. This initial study focuses on novice designers and aimed at establishing primary factors to address. However, final conclusions may only be possible by re addressing these initial findings and analyzing information from design practices performed by designers of different levels of skill and experience.

\section{Acknowledgements}

For their support, Cnpq (National Council for Scientific and Technological Development), Brazil, and Curtin University, Australia.

\section{References}

[1] Chakrabarti, A., et al., Computer-Based Design Synthesis Research: An Overview. Journal of Computing and Information Science in Engineering, 2011, 11(2): pp. 021003-021003.

[2] Oxman, R.E., Precedents in design: a computational model for the organization of precedent knowledge. Design Studies, 1994, 15(2): pp. 141-157.

[3] Eilouti, B.H., Design knowledge recycling using precedent-based analysis and synthesis models. Design Studies, 2009, 30(4): pp. 340-368. 
[4] Wiggins, G.E., Methodology in Architectural Design, in Department of Architecture. 1989, Massachusetts Institute of Technology: Cambridge. p. 174.

[5] Zarzycki, A., Light, materiality and narrative: beyond form-making in architecture, in ACM SIGGRAPH 2006 Research posters. 2006, ACM: Boston, Massachusetts. p. 20.

[6] Schön, D.A., Designing as reflective conversation with the materials of a design situation. Knowledge-Based Systems, 1992, 5(1): pp. 3-14.

[7] Thomas, K.L., Introduction: architecture and material practice, in Material matters: architecture and material practice, K.L. Thomas, Editor. 2007, Routledge: London. pp. 1-12.

[8] Fernandez, J., Material architecture: emergent materials for innovative buildings and ecological construction, John Fernandez. 2006, Amsterdam: Amsterdam: Architectural Press.

[9] Ashby, M.F., Materials and design: the art and science of material selection in product design, Mike Ashby, Kara Johnson. 2nd ed.. ed. K. Johnson. 2010, Oxford: Oxford: Butterworth-Heinemann.

[10] Wright, F.L., Frank Lloyd Wright: an autobiography. 1945, London: Faber.

[11] Van Hinte, E., C. Peeren, and J. Jongert, Superuse: Constructing New Architecture by Shortcutting Material Flows. 2007: 010 Publishers.

[12] Addis, W., Building with reclaimed components and materials: a design handbook for reuse and recycling, Bill Addis. 2012, London: Sterling, VA: Earthscan.

[13] Fry, T., Remakings: ecology, design, philosophy, 1994, Sydney: Envirobook.

[14] Design Council, Innovation by design, in How design enables science and technology research to achieve greater impact. 2014: London.

[15] Design Council, Eleven lessons: managing design in eleven global brands, in a study of the design process. 2007: London. p. 144.

[16] Jahan, A., et al., Material screening and choosing methods - A review. Materials and Design, 2010, 31(2): pp. 696-705.

[17] Wastiels, L. and I. Wouters, Material Considerations in Architectural Design: A Study of the Aspects Identified by Architects for Selecting Materials, in Undisciplined! Design Research Society Conference 2008. 2009, Sheffield Hallam University: Sheffield, UK.

[18] Akadiri, P.O. and P.O. Olomolaiye Development of sustainable assessment criteria for building materials selection. Engineering, Construction and Architectural Management, 2012, 19(6): pp. 666-687.

[19] Soliman, O.A., Perception of building materials in architecture. Journal of Engineering and Applied Science - Faculty of Engineering, Cairo University, 2013, 60(6). 